\title{
REVIEW Roles of PFKFB3 in cancer
}

\author{
Linlin Shi ${ }^{1}$, Hongming Pan $^{1,2}$, Zhen Liu', Jiansheng $\mathrm{Xie}^{2}$ and Weidong Han ${ }^{1,2}$
}

The understanding of 6-phosphofructo-2-kinase/fructose-2,6-biphosphatase 3 (PFK-2/FBPase 3, PFKFB3) has advanced considerably since its initial identification in human macrophages in the mid-1990s. As a vital regulator of glycolysis, accumulating studies have suggested that PFKFB3 is associated with many aspects of cancer, including carcinogenesis, cancer cell proliferation, vessel aggressiveness, drug resistance and tumor microenvironment. In this review, we summarize current knowledge of PFKFB3 regulation by several signal pathways and its function in cancer development in different cell types in cancer tissues. Ubiquitous PFKFB3 has emerged as a potential target for anti-neoplastic therapy.

Signal Transduction and Targeted Therapy (2017) 2, e17044; doi:10.1038/sigtrans.2017.44; published online 24 November 2017

\section{INTRODUCTION}

Glycolysis is the metabolic pathway that converts glucose to pyruvate. The free energy released in this process is utilized to form the high-energy compounds ATP and NADH. A high rate of glycolytic flux, even in the presence of oxygen, is a central metabolic hallmark of tumors. This phenomenon is historically known as the 'Warburg Effect'." The rate of glycolytic flux is controlled at different levels and by different mechanisms. One of the critical modulators is the conversion of fructose-6-phosphate (F6P) to fructose-1,6-bisphosphate $(\mathrm{F} 1,6 \mathrm{P} 2)$ by 6-phosphofructo-1kinase (PFK-1), which is the first committed rate-limiting step of glycolysis. ${ }^{2}$ The intracellular allosteric regulator fructose 2,6bisphosphate $(\mathrm{F} 2,6 \mathrm{P} 2)$ is a potent activator of PFK-1. ${ }^{3} \mathrm{~F} 2,6 \mathrm{P} 2$ increases the affinity of PFK-1 for F6P and overrides the tonic allosteric inhibition of PFK-1 by ATP, allowing glycolytic flux through the PFK-1 checkpoint and into F1,6P2 synthesis. ${ }^{3}$ The intracellular steady-state concentration of $\mathrm{F} 2,6 \mathrm{P} 2$ is controlled by a family of homodimeric and bifunctional enzyme PFK-2/FBPase (PFKFB) ${ }^{4,5}$ Despite the high sequence homology (85\%) of their core catalytic domains, the four isozymes of PFKFB (PFKFB1-4) display distinct properties, including tissue expression profiles, the ratio of their kinase/phosphatase activities, and their response to protein kinases, hormonal and growth factor signals. ${ }^{6,7}$ The bifunctional isoenzyme encoded by the pfkfb3 gene has the highest kinase: phosphatase activity ratio, which in turn sustains high glycolytic rates. ${ }^{8}$ Furthermore, PFKFB3 exists different spilce variants. For example, six splice variants of PFKFB3 have been found in the human brain. ${ }^{9}$ Confirming the activity and localization of these splice variants may help improve our understanding of the regulation of PFKFB3 and its function in tumor cell glycolysis, as well as its requirement for tumor growth.

The pfkfb3 gene is localized on chromosome 10p15.1 (ref. ${ }^{10}$ ) and contains multiple copies of the oncogene-like AUUUA instability element in its $3^{\prime}$ untranslated region ( $3^{\prime}$ UTR) (Figure 1a). ${ }^{11}$ The pfkfb3 gene contains at least 19 exons, and alternative splicing of the $\mathrm{COOH}$-terminal variable region leads to the expression of at least six structural isoforms, termed UBI2K1-6 in humans ${ }^{9}$ (Table 1). The PFKFB3 protein consists of two homodimers. The monomer structure is divided into two functional domains within the same polypeptide chain. ${ }^{4,7,12}$ The C-terminal domain contains the bisphosphatase activity of the enzyme. ${ }^{13-15}$ This domain catalyzes the hydrolytic degradation of $\mathrm{F} 2,6 \mathrm{P} 2$ into F6P and inorganic phosphate (Pi). The N-terminal domain is responsible for the synthesis of $\mathrm{F} 2,6 \mathrm{P} 2$ from $\mathrm{F} 6 \mathrm{P}$ and ATP (Figure 1b). ${ }^{14,16,17}$ The PFKFB3 protein is ubiquitously expressed, with especially high levels in proliferating tissues, transformed cells, solid tumors and leukemia cells. ${ }^{18}$ PFKFB3 expression could be upregulated in response to mitogenic, inflammatory and hypoxia stimuli and during the DNA synthesis phase of the cell cycle. ${ }^{18}$ Considering its significance in cancer metabolism, further explanation of the function of PFKFB3 in diverse cancers is necessary.

\section{REGULATORY MECHANISMS OF PFKFB3}

The oncogenic Ras signaling pathway has been invoked as a central regulator of the glucose metabolism of cancer via the activity of PFKFB3. ${ }^{19,20}$ Ras inhibition in glioblastoma downregulates hypoxia-inducible factor-1 alpha (HIF-1a), reducing the expression of the $p f k f b 3$ gene and causing glycolysis shutdown and cell death. ${ }^{21}$ Constitutive HER2 expression increases PFKFB3 expression and glucose metabolism in breast cancer cells. ${ }^{22}$ Loss of p53 and PTEN and/or other tumor suppressor functions also stimulates glycolysis in part by activating the regulatory bifunctional PFKFB3 family. ${ }^{23,24}$ In addition, the transcriptional corepressor myeloid translocation gene 16 (MTG16) could act as a brake on glycolysis, stimulating mitochondrial respiration and inhibiting cell proliferation through suppression of PFKFB3-4. ${ }^{25}$ Different stimuli have been reported to induce gene expression of pfkfb3. For example, hypoxia, ${ }^{26}$ progestin ${ }^{27}$ and estradiol ${ }^{28}$ induce PFKFB3 expression through interactions of HIF-1, progesterone receptor (PR), and estrogen receptor (ER) with their own consensus response elements located at the pfkfb3 promoter. Circadian-driven transcription factor 'CLOCK' could also bind to pfkfb3 promoter at 'E-box' site to increase the transcription of pfkfb3 in cancer cells. PFKFB3 inhibition significantly retarded the growth of implanted human tongue cancer cell in mice only at certain time points within the circadian cycle. This finding

${ }^{1}$ Department of Medical Oncology, Sir Run Run Shaw Hospital, College of Medicine, Zhejiang University, Hangzhou, Zhejiang, China and ${ }^{2}$ Laboratory of Cancer Biology, Institute of Clinical Science, Sir Run Run Shaw Hospital, College of Medicine, Zhejiang University, Hangzhou, Zhejiang, China.

Correspondence: J Xie (xjs85@126.com) or Professor W Han (hanwd@zju.edu.cn)

Received 13 April 2017; revised 22 June 2017; accepted 28 June 2017 
indicates the significance of time-based PFKFB3 inhibition in cancer treatment. ${ }^{29}$ Growth factors, such as insulin, ${ }^{30}$ proinflammatory molecules such as interleukin 6 (IL-6), lipopolysaccharide (LPS) and adenosine ${ }^{32}$ or different stress stimuli $(\mathrm{NaCl}$, $\mathrm{H}_{2} \mathrm{O}_{2}$, UV radiation or anisomycin) ${ }^{33}$, increase pfkfb3 gene expression levels. The major signal pathways involved in PFKFB3 regulation are shown in Figure 2.

The mRNAs of all PFKFB3 isoforms contain multiple copies of the AUUUA instability motif in their $3^{\prime}$ UTR AU-rich elements. ${ }^{34,35}$ It was reported recently that miR-206 and miR-26b directly interact with the $3^{\prime} U T R$ of PFKFB3 mRNA, resulting in attenuation of glycolysis in breast cancer and osteosarcoma, respectively. ${ }^{36,37}$ Other miRNAs, including hsa-miR-26b-5p and hsa-miR-330-3p, are also expected to have binding sites in the $3^{\prime} U T R$ of PFKFB3, although functional validation remains to be performed. ${ }^{37}$ The PFKFB3 isoenzyme is phosphorylated at a consensus site, Ser ${ }^{461}$, within the C-terminal region by mitogen-activated protein kinaseactivated protein kinase 2 (MK2), ${ }^{33}$ AMP-activated protein kinase (AMPK), ${ }^{38}$ protein kinase A (PKA) and protein kinase C (PKC), ${ }^{39}$ thus making it responsive to multiple external signals. $S$ glutathionylation $^{40}$ and demethylation ${ }^{41}$ of PFKFB3 induced by high reactive oxygen species (ROS) in cancer cells cause a shift of glucose utilization from glycolysis toward the NADPH-producing pentose phosphate pathway (PPP), resulting in ROS detoxification. The PFKFB3 isoenzyme is degraded by the E3 ubiquitin ligase
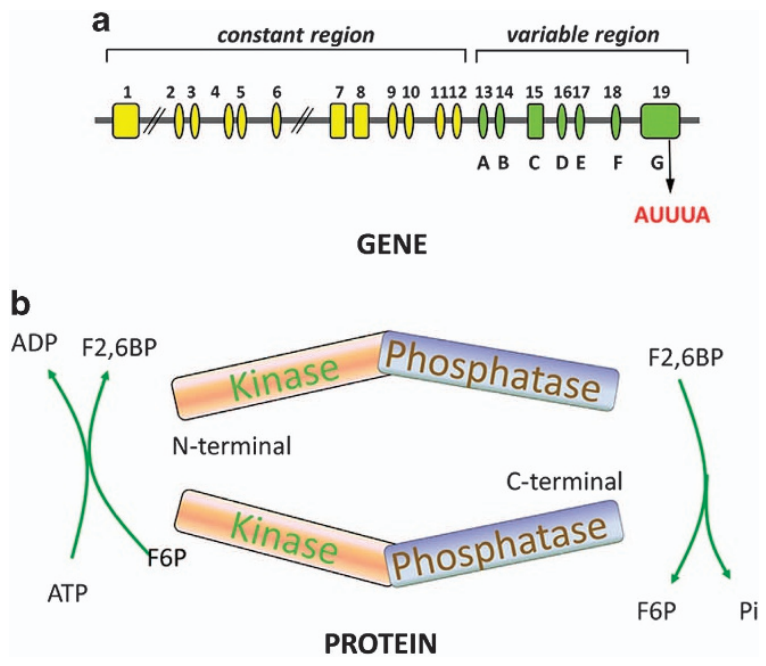

Figure 1. General structure of the PFKFB3 gene and protein. (a) The PFKFB3 gene contains at least 19 exons, which can be divided into 2 regions, the constant and variable regions. The variable region contains seven exons named $A-G$, and variations in the exons in this region leads to six isoforms of PFKFB3. PFKFB3 contains multiple copies of the AUUUA instability element in its $3^{\prime}$ UTR. (b) The PFKFB3 protein has two homodimeric subunits. Each subunit of PFKFB3 comprises two functional domains: an $\mathrm{N}$-terminal kinase domain and a C-terminal phosphatase domain. The kinase activity catalyzes the production of F2,6P2 and ADP from F6P and ATP, which highly promote the glycolytic pathway. The phosphatase activity dephosphorylates F2,6P2 to produce F6P and Pi. anaphase-promoting complex/cyclosome-cadherin1 (APC/CCdh1) via the KEN box. ${ }^{42} \mathrm{~A}$ decrease in the activity of APC/CCdh1 in mid-to-late $\mathrm{G} 1$ phase leads to the accumulation of PFKFB3. ${ }^{42}$ PFKFB3 is also a substrate for another ubiquitin ligase, SKP1-CUL1-F-box-protein (SCF), at the onset of S-phase via the DSG box, and thus the activity of PFKFB3 occurs in a short interval, coinciding with a peak in glycolysis in mid-to -late $\mathrm{G} 1{ }^{43}$ The findings led to the identification of the roles of these ubiquitin ligases in the metabolic regulation of the cell cycle and, consequently, cell proliferation. The degradation of PFKFB3 by those two enzymes induced by mitogenactivated protein kinase 14 (MAPK14) also leads to the reduction of ROS. ${ }^{44}$ The detoxification of ROS related to PFKFB3 is presented in Supplementary Figure 1. PFKFB3 is differentially regulated both at the transcriptional and post-transcriptional levels (Table 2).

\section{ROLES OF PFKFB3 BEYOND GLYCOLYSIS}

Although the glycolytic role of PFKFB3 in cancer progression has been the subject of numerous functional studies, some researchers have also focused on the functions of PFKFB3 beyond glycolysis. Recent observations have established that PFKFB3 is also trafficked to the nucleus in multiple cell lines via a highly conserved nuclear localization motif in the C-terminal domain, and ectopic expression of wild-type PFKFB3 in the nucleus stimulates cellular proliferation without an effect on glucose metabolism. ${ }^{45}$ The product of PFKFB3, F2,6P2, activates cyclin-dependent kinases (Cdks) and then stimulates the Cdk-mediated phosphorylation of the Cip/Kip protein p27, which in turn results in decreased levels of p27 due to ubiquitination and proteasomal degradation by Cdk1. ${ }^{45}$ As p27 is a potent suppressor of the G1/S transition and activator of apoptosis, the known requirement for PFKFB3 for cell cycle progression and prevention of apoptosis may be partly due to the ability of F2,6P2-induced p27 degradation. ${ }^{46,47}$ The effect of siRNA silencing of PFKFB3 is reversed by co-siRNA silencing of p27. ${ }^{47}$ These results confirm that PFKFB3 expression may not only be essential for the regulation of glycolysis in the cytoplasm, but also in the control of the cell cycle in the nucleus and maintenance of an anti-apoptotic state.

\section{ROLES OF PFKFB3 IN CANCER}

Loiseau et al. ${ }^{48}$ discovered that there was no bisphosphatase activity of PFKFB in hepatocellular carcinoma (HCC) cells, which was hypothesized as a key mechanism accounting for the loss of control of glycolysis. Although multiple PFKFB isoforms are almost certainly co-expressed in these tumor cells, the absence of bisphosphatase activity supports the explanation that the dominantly expressed PFKFB enzyme in these cells is PFKFB3. PFKFB3 has been suggested to play a crucial role in many types of tumor cells as well as various cells in the tumor microenvironment. The following sections and Figure 3 summarize recent advances of PFKFB3 in different tumor cells, tumor stem cells and tumor environment cells.

Table 1. Comparison of the nucleotide sequences and body localization of six ubiquitous PFKFB3 isoforms

\begin{tabular}{llll}
\hline Table 1. Comparison of the nucleotide sequences and body localization of six ubiquitous PFKFB3 isoforms \\
\hline Splice variants & Alias & Variable exons & Location \\
\hline UBI2K1 & & A, B, C, G & Low levels in the brain \\
UBI2K2 & A, C, D, E, G & Low levels in the brain \\
UBI2K3 & A, C, D, F, G & Brain-specific \\
UBI2K4 & Inducible PFK-2 & A, C, D, G & Preferentially expressed in human skeletal muscle \\
UBI2K5 & Placenta PFK-2/FBPase-2 ubiquitous PFK-2/FBPase-2 & A, C, G & Brain, liver, skeletal muscle \\
UBI2K6 & & A, G & Brain, liver, skeletal muscle \\
\hline
\end{tabular}




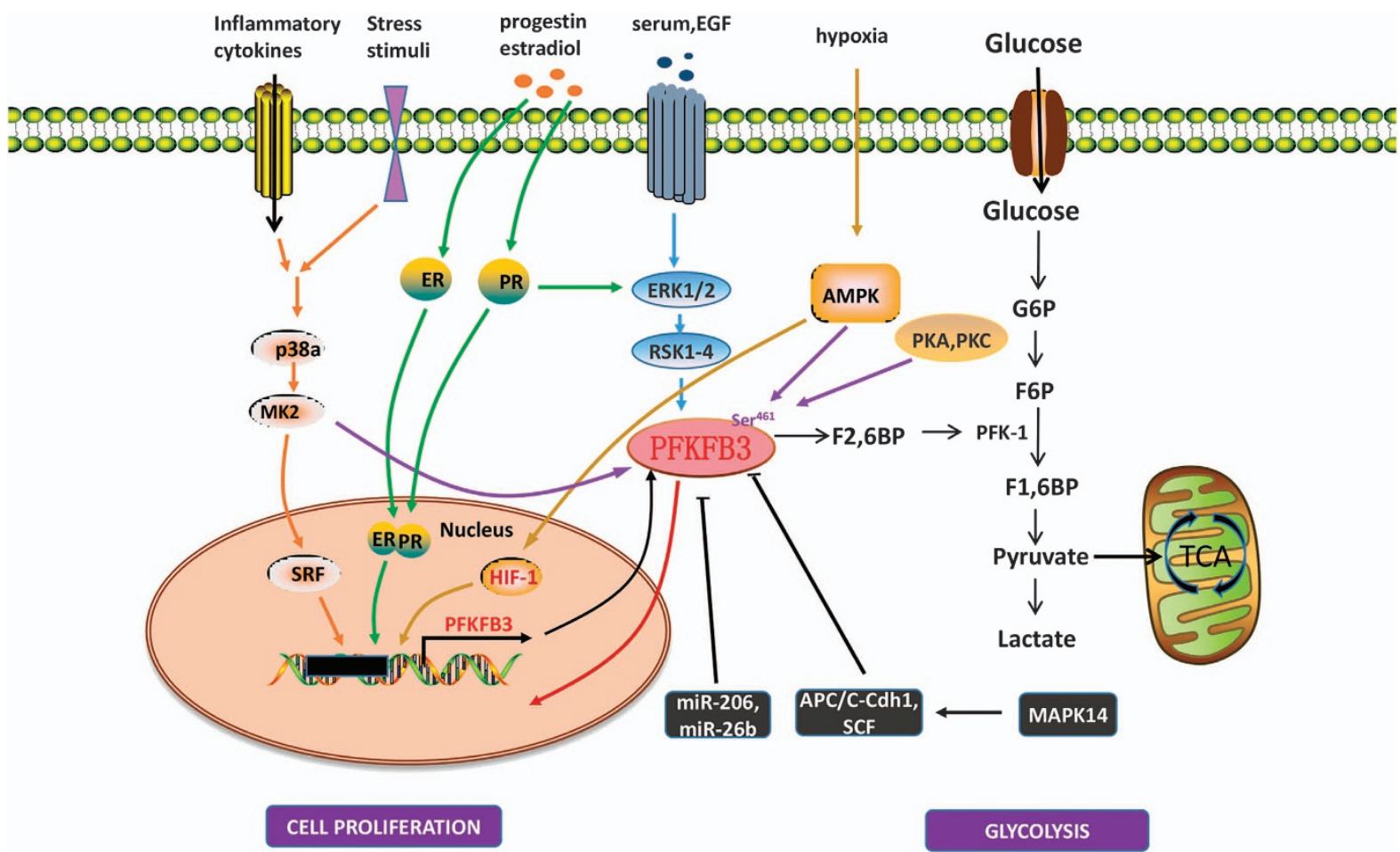

Figure 2. Signaling pathways involving PFKFB3. Numerous molecules are associated with PFKFB3 regulation. (1) Progestin, estradiol and hypoxia induce binding of the transcription factors PR, ER and HIF, respectively, to their responsive elements in the PFKFB3 promoter. Inflammatory cytokines and stress stimuli increase PFKFB3 production via the P38/MK2/SRF pathway. Serum and EGF function through the ERK1/2 (extracellular-signal-regulated kinase)/RSK1-4 (ribosomal S6 kinase) pathway, and progestin also regulates glycolysis through this pathway as a secondary mechanism. (2) MiR-206 and miR-26b inhibit PFKFB3 by interacting with 3'UTR of PFKFB3 mRNA. Other negative regulators of PFKFB3, such as ubiquitin ligase APC/C-Cdh1 and SCF, catalyze the degradation of the PFKFB3 protein, which in turn results in decreased glycolysis in cells. (3) PFKFB3 is phosphorylated at Ser ${ }^{461}$ within the C-terminal region by MK234, AMPK38, PKA and PKC.

Table 2. Regulatory mechanisms of PFKFB3

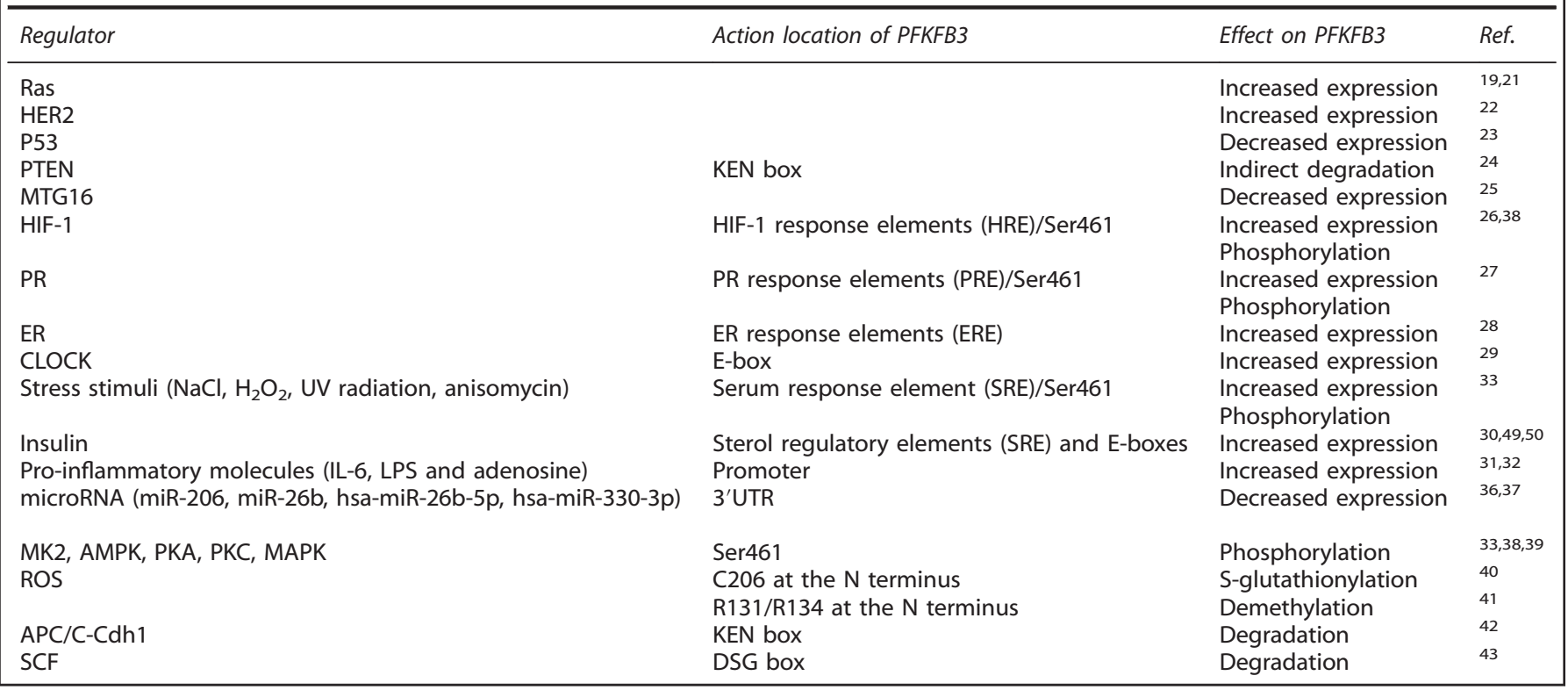

Targeting PFKFB3 in cancer cells

Enhanced glycolysis is important for cancer development. ${ }^{51}$ As a key regulator of glycolysis, PFKFB3 plays an important part in oncogenesis and the survival and proliferation of cancer cells in the tumor microenvironment. The roles of PFKFB3 in different cancer cell lines and possible mechanisms are summarized in
Table 3. PFKFB3 has been studied in various cancer cells. Most studies have demonstrated that cancer cell growth, proliferation, migration and metastasis are promoted when PFKFB3 expression is increased or the PFKFB3 isoenzyme is phosphorylated. In addition, gene expression inhibition by siRNA in HeLa cells ${ }^{47,52}$ and colon carcinoma cells, ${ }^{53}$ or by miRNA in breast cancer cells ${ }^{36}$ 


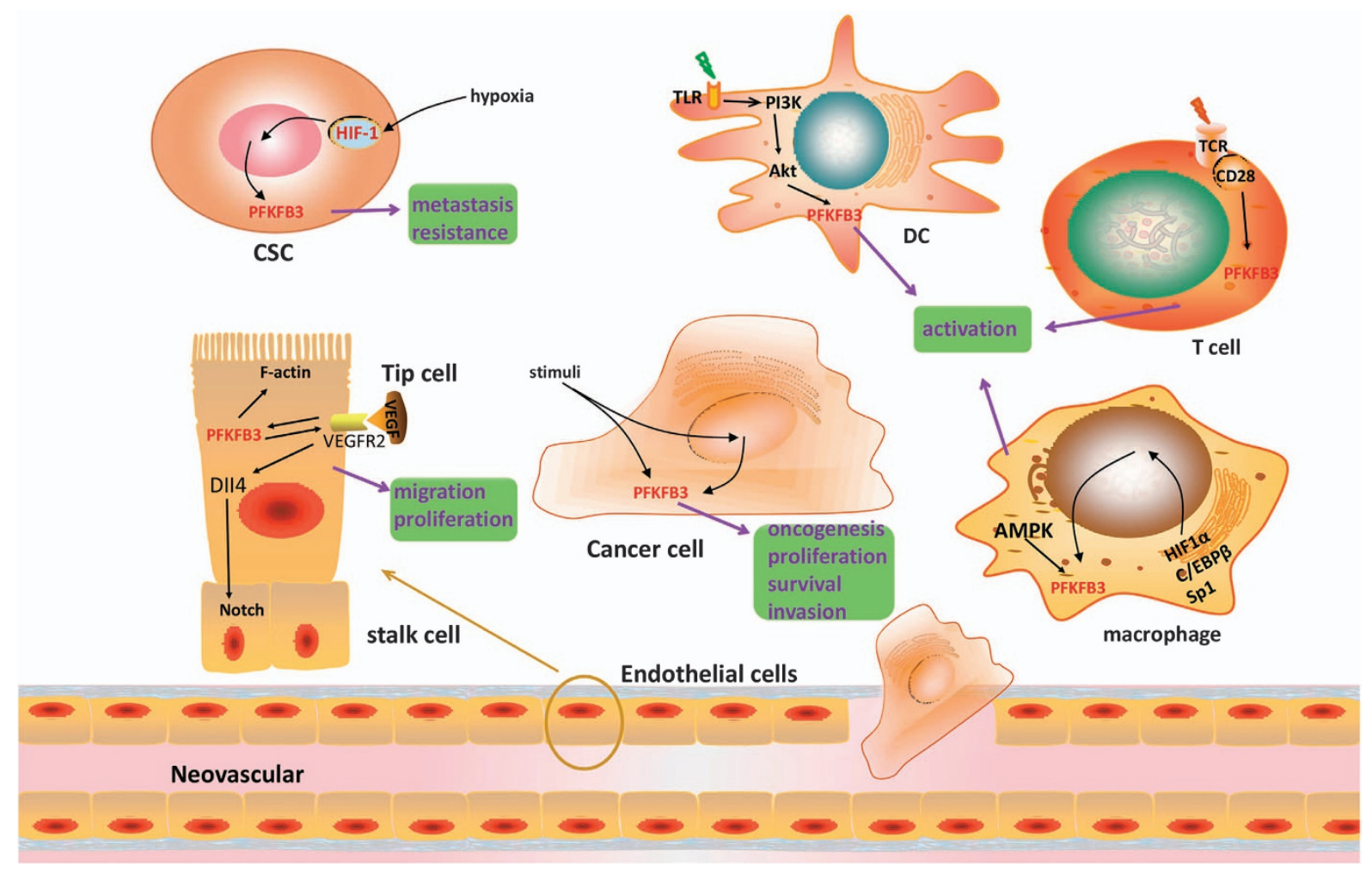

Figure 3. Roles of PFKFB3 in different cancer cells. High levels of the PFKFB3 isoenzyme have been proven to promote the oncogenesis, proliferation and survival of cancer cells. Elevated PFKFB3 in CSCs has been estimated to be related to distant metastasis and poor clinical outcome. PFKFB3 is apparently induced by hypoxia in CSCs. Silencing of PFKFB3 impairs vessel sprouting due to defects in both migrating tip and proliferating stalk cells. PFKFB3, compartmentalized with F-actin in lamellipodia, provide ATPs for vascular sprouting, and VEGFR2 induces PFKFB3 and activates Notch signaling. Immune cells shift from OXPHO to glycolysis when activated. The TLR/PI3K/Akt signaling pathway controls this shift in DC cells. In T cells, PFKFB3 is induced downstream by the TCR/CD28 receptor. PFKFB3 expression is increased by the transcription factors HIF1 $\alpha, \mathrm{C} / \mathrm{EBP} \beta$ and Sp1 in macrophages, and the PFKFB3 enzyme is phosphorylated by AMPK.

and osteosarcoma cells ${ }^{37,54}$ decreases the growth, proliferation and migration of these cells. PFKFB3 inhibitor 3-(3-pyridinyl)-1-(4pyridinyl)-2-propen-1-one (3PO) and its derivation 1-(4-pyridinyl)-3(2-quinolinyl)-2-propen-1-one (PFK15) have been shown to reduce glucose metabolism and exhibit potent antitumor activity in several human cancer xenograft models, including tongue carcinoma, gastric cancer and head and neck squamous cell carcinoma. ${ }^{29,55,56}$ These studies further proved the proto-oncogenic role of PFKFB3. A recent in vitro study found that PFKFB3 is a key effector protein of transforming growth factor $\beta 1$ (TGF $\beta 1$ ), which is an inducer of epithelial-mesenchymaltransition (EMT) in tumor cells, ${ }^{57}$ further suggesting a role of PFKFB3 in the cancer invasion process. Most of the literature has reported that increased PFKFB3 promotes tumorigenesis and proliferation. However, experimental result in astrocytoma cells is inconsistent. Zscharnack et $a l^{58}$ found that the PFKFB3 splice variant UBI2K4 is downregulated in high-grade astrocytoma relative to low-grade astrocytomas and corresponding non-neoplastic brain tissue. Overexpression of UBI2K4 decreased cell viability and anchorage-independent growth of U87 cells. Consequently, further study is needed to elaborate the exact role of PFKFB3 in different cancer cells.

Under different stimuli, the mechanisms involved in PFKFB3 regulation in different cancer cell lines differ. Even under the same stimuli, cancer cells also display diverse regulatory mechanisms for PFKFB3. For instance, under progestin stimulation, dual mechanisms operate to ensure glycolysis in breast cancer cells (increased expression and increased phosphorylation of PFKFB3). ${ }^{27}$ To protect cancer cells from harm from high ROS, HeLa cells and human leukemia U937 cells utilize two different modifications of PFKFB3 (Sglutathionylation and demethylation of PFKFB3). ${ }^{40,41}$ Desideri et al. ${ }^{44}$ suggested that decreased PFKFB3 entails loss of autophagy in HeLa cells, leading to increased resistance to nutrient deprivation. The possible mechanism is that ROS, a mild activator of autophagy, is detoxified by decreased PFKFB3 by shifting glycolysis to PPP. However, another study reported an opposite outcome that the selective inhibition of PFKFB3 induces increased autophagy in HCT-116 colon adenocarcinoma cells as a survival mechanism. ${ }^{53}$

Together, the roles of PFKFB3 on cancer cells are widely studied in cell lines and xenograft models. However, its functions and mechanisms are not exactly the same. A genetically engineered cancer in vivo model is still lacking for further investigation.

Targeting PFKFB3 in cancer stem cells (CSCs)

CSCs are a subgroup of cells within a tumor that have the ability of (1) self-renewal and differentiation into multiple cell types when transplanted; ${ }^{59}$ (2) initiating new tumors or responsible for the dissemination of metastases; ${ }^{60}$ (3) resisting to anticancer drugs or radiations. ${ }^{61,62}$ Pacini et al. ${ }^{63}$ suggest that the undifferentiated state of stem cells is characterized by a decrease in oxidative phosphorylation, a reduced level of intracellular ATP and a smaller production of ROS. CSCs from colon carcinoma, ${ }^{64}$ osteosarcoma, ${ }^{65}$ epithelial ovarian cancer ${ }^{66,67}$ and breast cancer ${ }^{68}$ ' were proved to rely on the glycolysis pathway rather than oxidative phosphorylation (OXPHOS) for their energy needs. However, leukemia ${ }^{69}$ and pancreatic adenocarcinoma ${ }^{70}$ support OXPHOS as the primary energy source of CSCs. Even in the same type of tumor CSCs, the glucose metabolic patterns from different studies differ. ${ }^{71,72}$ Nevertheless, the peculiar metabolic characteristic of CSCs becomes a therapeutic and diagnostic opportunity in cancer research.

$\mathrm{CD} 44^{+} \mathrm{CD} 24^{-}$breast cancer stem-like cells are enriched in tumor-initiating and chemotherapy-resistant cells. ${ }^{73,74}$ Pfkfb3 is 


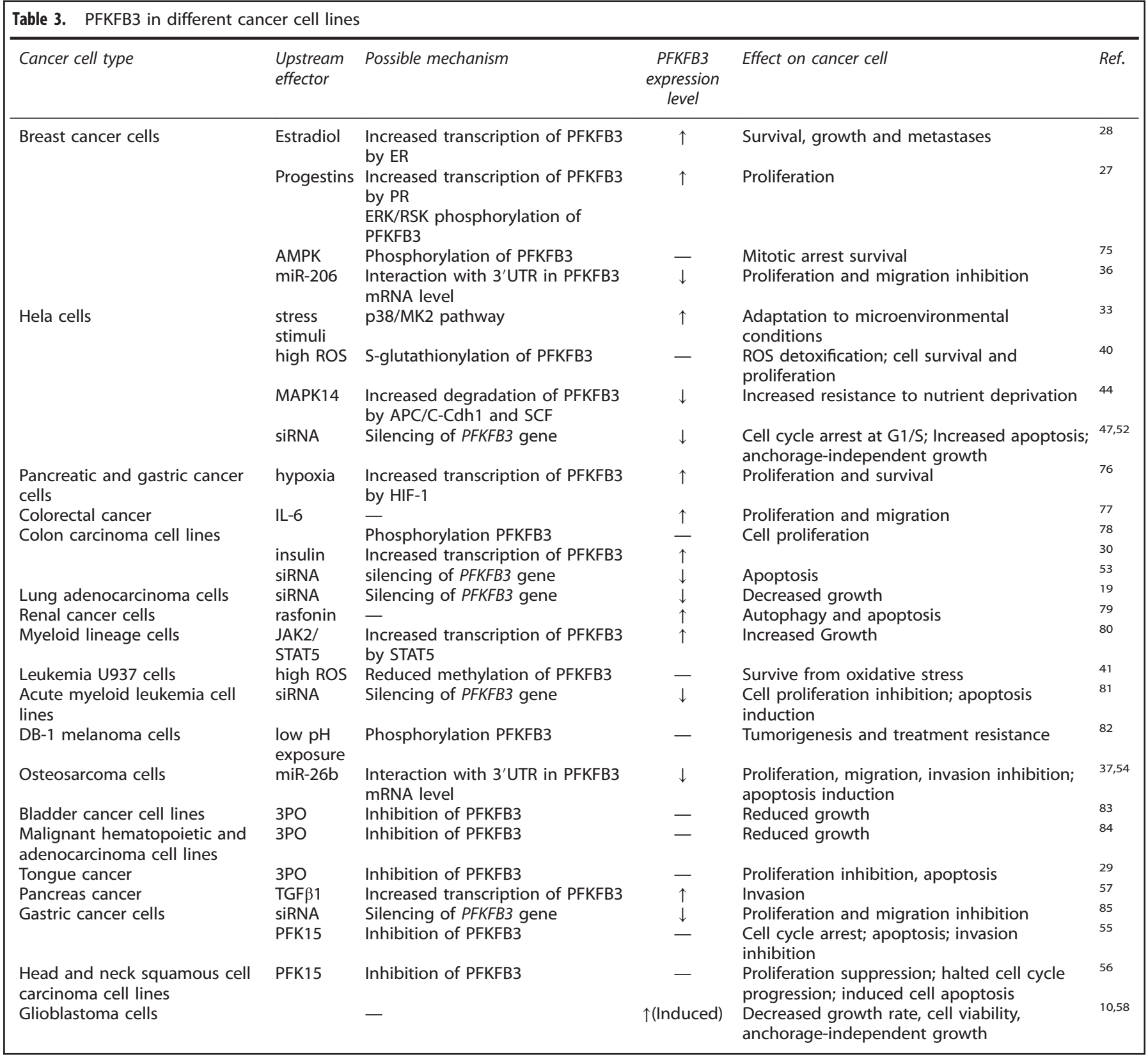

one of the genes in the $\mathrm{CD} 44^{+} \mathrm{CD} 24^{-}$cell gene signature that has been related to an enhanced risk of distant metastasis and poor clinical outcome in breast cancer patients. ${ }^{86,87}$ CieslarPobuda et al. $^{88}$ revealed that breast CSCs can be distinguished from induced pluripotent stem cells (iPS) or surrounding breast cancer cells based on differences in PFKFB3 and PFK-1 expression. They found that PFKFB3 and PFK-1 expression are higher in CSCs than in iPS cells. When cultured under hypoxic conditions, iPS cells and cancer cells change the expression levels of PFKFB3 and PFK-1 similarly in CSCs, supposing that CSCs might enhance glycolysis due to hypoxia-mediated modulation of restriction point (R-point) markers such as PFK-1 and PFKFB3. The different expression levels of PFKFB3 and PFK-1 among CSC, iPS cells and non-stem cancer cells suggest improved prospects for the more precise detection of CSCs and for clinical applications of stem cellbased therapies.
Targeting PFKFB3 in endothelial cells (ECs)

The blood vessel lumen is lined by a monolayer of ECs including tip cells and stalk cells, and each performs specific functions. ${ }^{89,90}$ ECs are also glucose addicted and highly glycolytic even in the presence of ample oxygen. ${ }^{91,92}$ A few possible explanations are as follows: (1) glycolysis generates ATP more rapidly to meet energy needs for EC motility compared to oxidative metabolism, thus quickly restoring more oxygen supply to the perivascular tissue; (2) glycolysis side pathways produce macromolecules needed for biomass duplication during cell division, which may further contribute to rapid vascular sprouting; (3) ECs can still depend on glycolysis to sprout in the milieu with less oxygen and glucose because glucose diffuses further away from vessels than oxygen; (4) by primarily maintaining glycolysis metabolism, ECs minimize the production of ROS, protecting ECs from their hyperoxic stress microenvironment. ${ }^{91,93-95}$ 
Tumor angiogenesis, represents one of the central hallmarks of cancer, is the growth of new blood vessels which supply nutrients for tumor growth, expansion and progression. ${ }^{96}$ High microvessel density in tumor specimen correlates metastasis, recurrence, poor prognosis in many malignancies. ${ }^{97,98}$ During angiogenesis, endothelial cells proliferate so that new capillary blood vessels can develop from preexisting microvessels to tolerate blood flow. Induction of PFKFB3 by vascular endothelial growth factor (VEGF) promotes angiogenesis and endothelial migration by regulating the tube formation of filopodia and lamellipodia and directional migration. Silencing of PFKFB3 in ECs reduces vascular sprouting by decreasing the migration of tip cells and proliferation of stalk cells. ${ }^{89,91,99,100}$ A few other mechanisms may also underlie this effect: (1) PFKFB3 compartmentalizes with F-actin in lamellipodia to create an assembly line of glycolysis, facilitating efficient and rapid local ATP production to fuel migration; ${ }^{91}$ (2) the increase in lactate upon increased PFKFB3 stimulates angiogenesis via activation of HIF-1a and upregulation of VEGF receptor 2 (VEGFR2); ${ }^{101}$ (3) PFKFB3 also control cell proliferation via glycolysis-independent Cdks activities in the nucleus. ${ }^{45}$

In contrast to traditional anti-angiogenic therapy that aims to inhibit angiogenesis, an emerging paradigm is to normalize characteristically chaotic tumor vasculature in order to improve blood perfusion, which could decrease hypoxia and increase drug accessibility. The normalized vessels might also resist shedding of cancer cells from the primary tumor, potentially reducing tumor metastasis. ${ }^{102,103}$ A recent study found that inhibition of PFKFB3 in melanoma tumor endothelial cells (TECs) induces tumor vessel normalization, thus reducing cancer cell invasion, intravasation and dissemination, and contributing to increased response to chemotherapy. ${ }^{104}$ This effect is probably achieved by reducing VEcadherin endocytosis and inflammation in ECs and making pericytes more quiescent and adhesive under reduced glycolysis. By decreasing NF-KB signaling, TECs also lower the expression of cancer cell adhesion molecules, which contributes to metastasis inhibition of cancer cells. ${ }^{104}$ Thus, targeting EC metabolism through PFKFB3 might offer unprecedented opportunities for anti-angiogenic therapies and inhibition of tumor growth.

\section{Targeting PFKFB3 in immune cells}

The Warburg effect has also recently been associated with many immune cell activities. For example, resting or quiescent $T$ cells will switch from OXPHOS to aerobic glycolysis to provide sufficient ATP and precursor molecules for proliferation and survival when encountering antigens. ${ }^{105-107}$ Chang et al. ${ }^{108}$ found that when activated $\mathrm{T}$ cells are provided with co-stimulation and growth factor stimulation but are blocked from engaging in glycolysis, their ability to produce interferon- $\gamma$ (IFN- $\gamma$ ) is markedly compromised. IFN $-\gamma$ is a cytokine contributing to the inhibition of the development of chemically or virus-induced tumors. ${ }^{109}$ T-cell activation is associated with a rapid increase in intracellular PFKFB3. PFKFB3 may be the dominant PFKFB family member involved in TCR/CD28-induced F2,6P2 synthesis and glycolysis. ${ }^{110}$ 3PO, an inhibitor of PFKFB3, can suppress T-cell-dependent immunity and induce apoptosis of T cells in vitro and in vivo. ${ }^{110}$ Researches on the roles of PFKFB3 in the antitumor immunity associated with $T$ cells mediated are still rare except the valuable work done by Chesney. They found a PFKFB3 inhibitor, PFK-158, could decrease tumor-infiltrating Th17 cells and myeloid-derived suppressor cells, and increase tumor-infiltrating $\mathrm{CD} 4^{+}$and $\mathrm{CD} 8^{+}$ $\mathrm{T}$ cells in the tumors of B16-F10 melanoma-bearing mice. ${ }^{11-113}$ However, the functions of different immune cells are different and complicated. Thus, a clarification of the function of PFKFB3 in different immune cells, immune responses and immune stages is necessary for a deeper understanding of the role of PFKFB3 in antitumor immunity.
Augmented aerobic glycolysis is also important for regulating the activation and function of dendritic cells (DC) and macrophages. ${ }^{32,114,115}$ DC activation and maturation are induced by Toll-like receptors (TLRs) ligands, stimulating a profound metabolic transition to aerobic glycolysis. The phosphatidylinositol 3'-kinase (PI3K)/Akt signaling pathway controls this metabolic switch. ${ }^{16}$ Increased PFKFB3 expression could be essential in protecting the viability of macrophages to develop their long-term defense and reparative functions in the inflammatory microenvironment. The expression of the transcription factors HIF1a, C/EBP $\beta$, and Sp1 is activated in macrophages treated with LPS. LPS also increases AMPK activity in macrophages, which increases PFKFB3 phosphorylation. ${ }^{32}$ Because these immune cell experiments were all performed in vitro and the cancer microenvironment in vivo is completely different, more studies in vivo and in cancer models are needed to illustrate the function of glycolysis in immune cells within cancer.

Chronic inflammation is acknowledged as the cause of various human cancers. ${ }^{117,118}$ For example, patients with inflammatory bowel disease have an increased risk for colorectal cancer (CRC). ${ }^{119,120}$ The AUUUA instability element found in the mRNA of pfkfb3 is also found in several inflammatory cytokine mRNAs (for example, IL-1, IFN- $\gamma$ and granulocyte/macrophage colonystimulating factor, GM-CSF). ${ }^{34,35,121}$ The inflammatory cytokine IL-6 stimulates aerobic glycolysis and promotes cell proliferation and migration in CRC cells. Pfkfb3 was the gene most downregulated by an anti-IL-6 receptor antibody in colorectal adenoma tissues. ${ }^{77}$ We therefore speculate that the tumor inflammatory environment could be alleviated through PFKFB3 inhibition.

\section{THERAPEUTIC POTENTIAL OF PFKFB3 INHIBITORS IN THE TREATMENT OF CANCER}

As knowledge of PFKFB3 in cancer metabolism accumulates, there has been an increased interest in the identification and development of PFKFB3 inhibitors. It is known that current standard chemotherapeutic and irradiation protocols mainly target rapidly dividing cells. The data from Liu et al. ${ }^{122}$ suggest the efficacy of these treatments could be enhanced by inhibition of glycolysis aimed specifically at slower growing cancer cells.

$3 \mathrm{PO}$ is a well-studied suppressor of the basal catalytic activity of the PFKFB3 isozyme. It decreases intracellular F2,6P2, thus suppressing glycolytic flux in transformed cells. 3PO functions through its binding to the sites that the PFKFB3 protein binds and functions. Consequently, binding competition between $3 \mathrm{PO}$ and F6P for the binding area is possible. ${ }^{84}$ However, Lineweaver-Burk double-reciprocal plot analyses have shown that $3 \mathrm{PO}$ exhibits a complex mechanism in the inhibition of PFK-2 activity that is both competitive and uncompetitive. Introduction of $3 \mathrm{PO}$ to various cancer cells, such as breast cancer, ${ }^{123}$ bladder carcinoma cancer $^{83}$ and hepatocellular carcinoma ${ }^{84}$ induces cytotoxicity, apoptosis and growth inhibition. An advantage is that $3 \mathrm{PO}$ and its optimized derivatives do not affect serum glucose, red blood cell and white blood cell concentrations when administered daily in vivo. ${ }^{110}$

PFK15, a potent derivation of 3PO, was recently demonstrated $^{55,56}$ to (1) cause cell cycle arrest in G0/G1 phase by blocking the cyclin-CDKs/Rb/E2F signaling pathway; (2) induce apoptosis through mitochondria; (3) inhibit invasion by downregulating focal adhesion kinase (FAK) and upregulating E-cadherin. Additionally, compared with other PFKFB3 inhibitors, PFK15 displays potent and selective activity against PFKFB3 with low cytotoxicity. ${ }^{55,124}$ The improved apoptosis potency of PFK15 was greater than the metabolic changes it induced. ${ }^{124}$ Another potent and selective inhibitor of PFKFB3, PFK-158, displays broad antitumor activity and immunomodulatory effects in multiple human and syngeneic preclinical models. ${ }^{111-113}$ A phase I clinical trial demonstrated that PFK-158 was successfully completed in 
July 2016. PFK-158 presented safety and anticancer activity in 6 of 19 evaluable patients with various advanced solid tumors (http:// www. advancedcancertherapeutics.com). Other inhibitors of PFKFB3 have also been identified, such as 5-triazolo-2-arylpyridazinone, ${ }^{125}$ 1-(3-pyridinyl)-3-(2-quinolinyl)-2-propen-1-one (PQP), ${ }^{126} \quad 5,6,7$, 8-tetrahydroxy-2-(4-hydroxyphenyl) chrome-4-one (N4A) and 7, 8dihydroxy-3-(4-hydroxyphenyl) chromen-4-one (YN1). ${ }^{127}$ The further identification of small-molecule inhibitors of PFKFB3 may provide a new avenue for the development of novel chemotherapeutic agents.

\section{CONCLUSION AND PERSPECTIVES}

Knowledge of the function of PFKFB3 in cancer has advanced considerably in the past several years. In this review, we summarized the function of PFKFB3 in tumor metabolism and elucidated the regulatory mechanisms of PFKFB3. Furthermore, the role of PFKFB3 in human tumor cells, CSCs, ECs and immune cells, was discussed in this review. PFKFB3 represents a promising target for tumor treatment. However, until now, no PFKFB3 inhibitors have been approved to treat patients with cancer. 3PO is a potent inhibitor of PFKFB3 but poor water solubility makes this compound clinically unavailable. Other potent and selective inhibitors of PFKFB3, such as PFK15 and PFK-158, are under clinical trials for treating late-stage cancer patients. Recently emerged nanotechnology-based drug delivery carriers ${ }^{128-130}$ have the ability to formulate various hydrophobic anticancer agents including $3 \mathrm{PO}^{131}$ thereby showing the potentials to improve the anticancer efficacy when used in vivo. On the other hand, specifying resistance mechanisms triggered by targeted therapies would allow for the specific selection of drug combinations.

It was recently demonstrated that lactic acidosis arising as a result of tumor metabolism allows cancer cells to develop strong resistance to glucose deprivation-induced cell death. ${ }^{132}$ The theory that changing the $\mathrm{pH}$ of the tumor microenvironment with bicarbonate has been successfully applied in clinical treatment for patients with HCC that is not amenable to surgery, ${ }^{133}$ which provided new insights into treating tumors by targeting their metabolism and microenvironment. Reasonably, we believe combining PFKFB3 inhibitor with environmental cells inhibition, such as immune suppressors or angiogenesis inhibitors, would probably generate a better effect of tumor eradication. For example, the PFKFB3 inhibitor PFK-158 could improve the antitumor activity of the immune checkpoint inhibitor antiCTLA4 in the B16 mouse model. ${ }^{112}$ Furthermore, tumors could rely on other metabolic pathways for energy supply besides glycolysis. For example, increased cholesterol synthesis and steroidogenesis occur throughout prostate cancer carcinogenesis rather than the classic 'glycolytic switch' observed in the majority of other solid tumors. ${ }^{134,135}$ Increased fatty acid oxidation is sufficient for cell survival and to protect cells from glucose withdrawal-induced death in Akt-overexpressing glioblastoma. ${ }^{136}$ A synergistic anti-neoplastic effect of anti-metabolism agents is anticipated when combined with chemotherapeutic drugs. How these drugs interact and produce optimal effects warrants further investigations.

\section{ACKNOWLEDGEMENTS}

This work was supported by the National Natural Science Foundation of China (81372621, 81572361, 81502398 and 81602635), the Zhejiang Province Preeminence Youth Fund (LR16H160001) and the Zhejiang Natural Sciences Foundation Grant (Q16H160019).

\section{COMPETING INTERESTS}

The authors declare no conflict of interest.

\section{REFERENCES}

1 Warburg O. On the origin of cancer cells. Science 1956; 123: 309-314.

2 Weber G. Enzymology of cancer cells (first of two parts). N Engl J Med 1977; 296: 486-449.

3 Van Schaftingen E, Jett MF, Hue L, Hers HG. Control of liver 6-phosphofructokinase by fructose 2,6-bisphosphate and other effectors. Proc Natl Acad Sci Biol 1981; 78: 3483-3486.

4 Pilkis SJ, Claus TH, Kurland IJ, Lange AJ. 6-Phosphofructo-2-kinase/fructose-2, 6-bisphosphatase: a metabolic signaling enzyme. Annu Rev Biochem 1995; 64: 799-835.

5 Okar DA, Lange AJ. Fructose-2,6-bisphosphate and control of carbohydrate metabolism in eukaryotes. Biofactors 1999; 10: 1-14.

6 El-Maghrabi MR, Noto F, Wu N, Manes N. 6-Phosphofructo-2-kinase/fructose-2, 6-bisphosphatase: suiting structure to need, in a family of tissue-specific enzymes. Curr Opin Clin Nutr Metab 2001; 4: 411-418.

7 Okar DA, Lange AJ, Manzano À, Navarro-Sabatè A, Riera LS, Bartrons R. PFK-2/ FBPase-2: maker and breaker of the essential biofactor fructose-2,6-bisphosphate. Trends Biochem Sci 2001; 26: 30-35.

8 Sakakibara R, Kato M, Okamura N, Nakagawa T, Komada Y, Tominaga N et al. Characterization of a human placental fructose-6-phosphate, 2-kinase/fructose2,6-bisphosphatase. J Biochem 1997; 122: 122-128.

9 Kessler R, Eschrich K. Splice isoforms of ubiquitous 6-phosphofructo-2-kinase/ fructose-2,6-bisphosphatase in human brain. Brain Res Mol Brain Res 2001; 87: 190-195.

10 Fleischer M, Kessler R, Klammer A, Warnke JP, Eschrich K. LOH on 10p14-p15 targets the PFKFB3 gene locus in human glioblastomas. Genes Chromosomes Cancer 2011; 50: 1010-1020.

11 Chesney J, Telang S, Fau-Yalcin A, Yalcin A, Fau-Clem A, Clem A, Fau-Wallis N, Wallis N, Fau-Bucala R, Bucala R. Targeted disruption of inducible 6phosphofructo-2-kinase results in embryonic lethality. Biochem Biophys Res Commun 2005; 331: 139-146.

12 El-Maghrabi MR, Claus TH, Pilkis J, Fox E, Pilkis SJ. Regulation of rat liver fructose 2,6-bisphosphatase. J Biol Chem 1982; 257: 7603-7607.

13 Tauler A, Lin K, Pilkis SJ. Hepatic 6-phosphofructo-2-kinase/fructose-2,6-bisphosphatase. Use of site-directed mutagenesis to evaluate the roles of His-258 and His-392 in catalysis. J Biol Chem 1990; 265: 15617-15622.

14 Li L, Lin K, Pilkis J, Correia JJ, Pilkis SJ. Hepatic 6-phosphofructo-2-kinase/fructose2,6-bisphosphatase. The role of surface loop basic residues in substrate binding to the fructose-2,6-bisphosphatase domain. J Biol Chem 1992; 267: 21588-21594.

15 Lin K, Li L, Correia JJ, Pilkis SJ. Glu327 is part of a catalytic triad in rat liver fructose-2,6-bisphosphatase. J Biol Chem 1992; 267: 6556-6562.

16 Kurland I, Chapman B, Lee YH, Pilkis S. Evolutionary reengineering of the phosphofructokinase active site: ARG-104 does not stabilize the transition state in 6-phosphofructo-2-kinase. Biochem Biophys Res Commun 1995; 213: 663-672.

17 Rider MH, Bertrand L, Vertommen D, Michels PA, Rousseau GG, Hue L. 6-phosphofructo-2-kinase/fructose-2,6-bisphosphatase: head-to-head with a bifunctional enzyme that controls glycolysis. Biochem J 2004; 381: 561-579.

18 Toshiya A, Jason C, Christine M, Lin L, Seamas D, Zenji M et al. High expression of inducible 6-phosphofructo-2-kinase/fructose-2,6-bisphosphatase (iPFK-2; PFKFB3) in human cancers. Cancer Res 2002; 62: 5881-5887.

19 Telang S, Yalcin A, Clem AL, Bucala R, Lane AN, Eaton JW et al. Ras transformation requires metabolic control by 6-phosphofructo-2-kinase. Oncogene 2006; 25: 7225-7234.

20 Kole HK, Resnick RJ, Van Doren M, Racker E. Regulation of 6-phosphofructo-1kinase activity in ras-transformed rat-1 fibroblasts. Arch Biochem Biophys 1991; 286: 586-590.

21 Blum R, Jacob-Hirsch J, Amariglio N, Rechavi G, Kloog Y. Ras inhibition in glioblastoma down-regulates hypoxia-inducible factor-1alpha, causing glycolysis shutdown and cell death. Cancer Res 2005; 65: 999-1006.

22 O'Neal J, Clem A, Reynolds L, Dougherty S, Imbert-Fernandez Y, Telang S et al. Inhibition of 6-phosphofructo-2-kinase (PFKFB3) suppresses glucose metabolism and the growth of HER2+ breast cancer. Breast Cancer Res Treat 2016; 160: 29-40.

23 Zawacka-Pankau J, Grinkevich VV, Huenten S, Nikulenkov F, Gluch A, Li H et al. Inhibition of glycolytic enzymes mediated by pharmacologically activated p53 targeting Warburg effect to fight cancer. J Biol Chem 2011; 286: 41600-41615.

24 Cordero-Espinoza L, Hagen T. Increased concentrations of fructose 2,6-bisphosphate contribute to the Warburg effect in phosphatase and tensin homolog (PTEN)-deficient cells. J Biol Chem 2013; 288: 36020-36028.

25 Kumar P, Sharoyko VV, Spegel P, Gullberg U, Mulder H, Olsson I et al. The transcriptional co-repressor myeloid translocation gene 16 inhibits glycolysis and stimulates mitochondrial respiration. PLOS ONE 2013; 8: e68502.

26 Fukasawa M, Tsuchiya T, Takayama E, Shinomiya N, Uyeda K, Sakakibara R et al. Identification and characterization of the hypoxia-responsive element of the 
human placental 6-phosphofructo-2-kinase/fructose-2,6-bisphosphatase gene. J Biochem 2004; 136: 273-277.

27 Novellasdemunt L, Obach M, Millan-Arino L, Manzano A, Ventura F, Rosa JL et al. Progestins activate 6-phosphofructo-2-kinase/fructose-2,6-bisphosphatase 3 (PFKFB3) in breast cancer cells. Biochem J 2012; 442: 345-356.

28 Imbert-Fernandez Y, Clem BF, O'Neal J, Kerr DA, Spaulding R, Lanceta L et al. Estradiol stimulates glucose metabolism via 6-phosphofructo-2-kinase (PFKFB3). J Biol Chem 2014; 289: 9440-9448.

29 Chen LL, Zhao JJ, Tang QM, Li HG, Zhang CG, Yu R et al. PFKFB3 control of cancer growth by responding to circadian clock outputs. Sci Rep 2016; 6: 24324.

30 Riera L, Manzano A, Navarro-Sabate A, Perales JC, Bartrons R. Insulin induces PFKFB3 gene expression in HT29 human colon adenocarcinoma cells. Biochim Biophys Acta 2002; 1589: 89-92.

31 Ando M, Uehara I, Kogure K, Asano Y, Nakajima W, Abe Y et al. Interleukin 6 enhances glycolysis through expression of the glycolytic enzymes hexokinase 2 and 6-phosphofructo-2-kinase/fructose-2,6-bisphosphatase-3. J Nippon Med Sch 2010; 77: 97-105.

32 Ruiz-Garcia A, Monsalve E, Novellasdemunt L, Navarro-Sabate A, Manzano A, Rivero $S$ et al. Cooperation of adenosine with macrophage Toll-4 receptor agonists leads to increased glycolytic flux through the enhanced expression of PFKFB3 gene. J Biol Chem 2011; 286: 19247-19258.

33 Novellasdemunt L, Bultot L, Manzano A, Ventura F, Rosa JL, Vertommen D et al. PFKFB3 activation in cancer cells by the p38/MK2 pathway in response to stress stimuli. Biochem J 2013; 452: 531-543.

34 Chesney J, Mitchell R, Benigni F, Bacher M, Spiegel L, Al-Abed $\mathrm{Y}$ et al. An inducible gene product for 6-phosphofructo-2-kinase with an AU-rich instability element: role in tumor cell glycolysis and the Warburg effect. Proc Natl Acad Sci USA 1999; 96: 3047-3052.

35 Chen $\mathrm{CY}$, Shyu AB. AU-rich elements: characterization and importance in mRNA degradation. Trends Biochem Sci 1995; 20: 465-470.

36 Ge X, Lyu P, Cao Z, Li J, Guo G, Xia W et al. Overexpression of miR-206 suppresses glycolysis, proliferation and migration in breast cancer cells via PFKFB3 targeting. Biochem Biophys Res Commun 2015; 463: 1115-1121.

37 Du JY, Wang LF, Wang Q, Yu LD. miR-26b inhibits proliferation, migration, invasion and apoptosis induction via the downregulation of 6-phosphofructo-2kinase/fructose-2,6-bisphosphatase-3 driven glycolysis in osteosarcoma cells. Oncol Rep 2015; 33: 1890-1898.

38 Marsin AS, Bouzin C, Bertrand L, Hue L. The stimulation of glycolysis by hypoxia in activated monocytes is mediated by AMP-activated protein kinase and inducible 6-phosphofructo-2-kinase. J Biol Chem 2002; 277: 30778-30783.

39 Okamura N, Sakakibara R. A common phosphorylation site for cyclic AMPdependent protein kinase and protein kinase $C$ in human placental 6-phosphofructo-2-kinase/fructose-2,6-bisphosphatase. Biosci Biotechnol Biochem 1998; 62: 2039-2042.

40 Seo $M$, Lee YH. PFKFB3 regulates oxidative stress homeostasis via its S-glutathionylation in cancer. J Mol Biol 2014; 426: 830-842.

41 Yamamoto T, Takano N, Ishiwata K, Ohmura M, Nagahata Y, Matsuura T et al. Reduced methylation of PFKFB3 in cancer cells shunts glucose towards the pentose phosphate pathway. Nat Commun 2014; 5: 3480.

42 Herrero-Mendez A, Almeida A, Fernandez E, Maestre C, Moncada S, Bolanos JP. The bioenergetic and antioxidant status of neurons is controlled by continuous degradation of a key glycolytic enzyme by APC/C-Cdh1. Nat Cell Biol 2009; 11: 747-752.

43 Tudzarova S, Colombo SL, Stoeber K, Carcamo S, Williams GH, Moncada S. Two ubiquitin ligases, APC/C-Cdh1 and SKP1-CUL1-F (SCF)-beta-TrCP, sequentially regulate glycolysis during the cell cycle. Proc Natl Acad Sci USA 2011; 108: 5278-5283.

44 Desideri E, Vegliante R, Cardaci S, Nepravishta R, Paci M, Ciriolo MR. MAPK14/ p38a-dependent modulation of glucose metabolism affects ROS levels and autophagy during starvation. Autophagy 2014; 10: 1652-1665.

45 Yalcin A, Clem BF, Simmons A, Lane A, Nelson K, Clem AL, Brock E et al. Nuclear targeting of 6-phosphofructo-2-kinase (PFKFB3) increases proliferation via cyclindependent kinases. J Biol Chem 2009; 284: 24223-24232.

46 Wang XT, Gorospe M, Huang Y, Holbrook NJ. p27(Kip1) overexpression causes apoptotic death of mammalian cells. Oncogene 1997; 15: 2991-2997.

47 Yalcin A, Clem BF, Imbert-Fernandez Y, Ozcan SC, Peker S, O'Neal J et al. 6Phosphofructo-2-kinase (PFKFB3) promotes cell cycle progression and suppresses apoptosis via Cdk1-mediated phosphorylation of p27. Cell Death Dis 2014; 5: e1337.

48 Loiseau AM, Rider MH, Foret D, Rousseau GG, Hue L. Rat hepatoma (HTC) cell 6phosphofructo-2-kinase differs from that in liver and can be separated from fructose-2,6-bisphosphatase. Eur J Biochem 1988; 175: 27-32.

49 Foretz M, Guichard C, Ferre P, Foufelle F. Sterol regulatory element binding protein-1c is a major mediator of insulin action on the hepatic expression of glucokinase and lipogenesis-related genes. Proc Natl Acad Sci USA 1999; 96 : $12737-12742$

50 Vaulont S, Vasseur-Cognet M, Kahn A. Glucose regulation of gene transcription. J Biol Chem 2000; 275: 31555-31558.

51 Warburg $\mathrm{O}$, Wind F, Negelein E. The metabolism of tumors in the body. Arch Int Pharmacodyn Ther 1952; 88: 473-481.

52 Calvo MN, Bartrons R, Castano E, Perales JC, Navarro-Sabate A, Manzano A. PFKFB3 gene silencing decreases glycolysis, induces cell-cycle delay and inhibits anchorage-independent growth in HeLa cells. FEBS Lett 2006; 580: 3308-3314.

53 Klarer AC, O'Neal J, Imbert-Fernandez Y, Clem A, Ellis SR, Clark J et al. Inhibition of 6-phosphofructo-2-kinase (PFKFB3) induces autophagy as a survival mechanism. Cancer Metab 2014; 2: 2.

54 Zheng WD, Zhou FL, Lin N. MicroRNA-26b inhibits osteosarcoma cell migration and invasion by down-regulating PFKFB3 expression. Genet Mol Res 2015; 14: 16872-16879.

55 Zhu W, Ye L, Zhang J, Yu P, Wang H, Ye Z et al. PFK15, a small molecule inhibitor of PFKFB3, induces cell cycle arrest, apoptosis and inhibits invasion in gastric cancer. PLOS ONE 2016; 11: e0163768.

56 Li HM, Yang JG, Liu ZJ, Wang WM, Yu ZL, Ren JG et al. Blockage of glycolysis by targeting PFKFB3 suppresses tumor growth and metastasis in head and neck squamous cell carcinoma. J Exp Clin Cancer Res 2017; 36: 7.

57 Yalcin A, Solakoglu TH, Ozcan SC, Guzel S, Peker S, Celikler S et al. 6-phosphofructo-2-kinase/fructose 2,6-bisphosphatase-3 is required for transforming growth factor $\beta 1$-enhanced invasion of Panc1 cells in vitro. Biochem Biophys Res Commun 2017; 484: 687-693.

58 Zscharnack K, Kessler R, Bleichert F, Warnke JP, Eschrich K. The PFKFB3 splice variant UBI2K4 is downregulated in high-grade astrocytomas and impedes the growth of U87 glioblastoma cells. Neuropathol Appl Neurobiol 2009; 35: 566-578.

59 Wicha MS, Liu SL, Dontu G. Cancer stem cells: an old idea-a paradigm shift. Cancer Res 2006; 66: 1883-1890.

60 Rhim AD, Mirek ET, Aiello NM, Maitra A, Bailey JM, McAllister F et al. EMT and dissemination precede pancreatic tumor formation. Cell 2012; 148: 349-361.

61 Vaz AP, Ponnusamy MP, Rachagani S, Dey P, Ganti AK, Batra SK. Novel role of pancreatic differentiation 2 in facilitating self-renewal and drug resistance of pancreatic cancer stem cells. Br J Cancer 2014; 111: 486-496.

62 Dean M, Fojo T, Bates S. Tumour stem cells and drug resistance. Nat Rev Cancer 2005; 5: 275-284.

63 Pacini N, Borziani F. Cancer stem cell theory and the warburg effect, two sides of the same coin? Int J Mol Sci 2014; 15: 8893-8930.

64 Emmink BL, Verheem A, Van Houdt WJ, Steller EJA, Govaert KM, Pham TV et al. The secretome of colon cancer stem cells contains drug-metabolizing enzymes. J Proteomics 2013; 91: 84-96.

65 Palorini R, Votta G, Balestrieri C, Monestiroli A, Olivieri S, Vento R et al. Energy metabolism characterization of a novel cancer stem cell-like line 3AB-OS. J Cell Biochem 2014; 115: 368-379.

66 Alvero AB, Montagna MK, Sumi NJ, Joo WD, Graham E, Mor G. Multiple blocks in the engagement of oxidative phosphorylation in putative ovarian cancer stem cells: implication for maintenance therapy with glycolysis inhibitors. Oncotarget 2014; 5: 8703-8715.

67 Liao JQ, Qian F, Tchabo N, Mhawech-Fauceglia P, Beck A, Qian ZK et al. Ovarian cancer spheroid cells with stem cell-like properties contribute to tumor generation, metastasis and chemotherapy resistance through hypoxia-resistant metabolism. PLOS ONE 2014; 9: e84941.

68 Dong C, Yuan T, Wu Y, Wang Y, Fan TW, Miriyala S et al. Loss of FBP1 by Snailmediated repression provides metabolic advantages in basal-like breast cancer. Cancer Cell 2013; 23: 316-331.

69 Lagadinou ED, Sach A, Callahan K, Rossi RM, Neering SJ, Minhajuddin M et al. BCL-2 inhibition targets oxidative phosphorylation and selectively eradicates quiescent human leukemia stem cells. Cell Stem Cell 2013; 12: 329-341.

70 Viale A, Pettazzoni P, Lyssiotis CA, Ying HQ, Sanchez N, Marchesini M et al. Oncogene ablation-resistant pancreatic cancer cells depend on mitochondrial function. Nature 2014; 514: 628-632.

71 Zhou YF, Zhou Y, Shingu T, Feng L, Chen Z, Ogasawara M et al. Metabolic alterations in highly tumorigenic glioblastoma cells preference for hypoxia and high dependency on glycolysis. J Biol Chem 2011; 286: 32843-32853.

72 Janiszewska M, Suva ML, Riggi N, Houtkooper RH, Auwerx J, Clement-Schatlo V et al. Imp2 controls oxidative phosphorylation and is crucial for preserving glioblastoma cancer stem cells. Gene Dev 2012; 26: 1926-1944.

73 Creighton CJ, Li XX, Landis M, Dixon JM, Neumeister VM, Sjolund A et al. Residual breast cancers after conventional therapy display mesenchymal as well as tumor-initiating features. Proc Natl Acad Sci USA 2009; 106: 13820-13825. 
74 Li XX, Lewis MT, Huang J, Gutierrez C, Osborne CK, Wu MF et al. Intrinsic resistance of tumorigenic breast cancer cells to chemotherapy. J Natl Cancer I 2008; 100: 672-679.

75 Domenech E, Maestre C, Esteban-Martinez L, Partida D, Pascual R, FernandezMiranda G et al. AMPK and PFKFB3 mediate glycolysis and survival in response to mitophagy during mitotic arrest. Nat Cell Biol 2015; 17: 1304-1316.

76 Minchenko OH, Tsuchihara K, Minchenko DO, Bikfalvi A, Esumi H. Mechanisms of regulation of PFKFB expression in pancreatic and gastric cancer cells. World $J$ Gastroenterol 2014; 20: 13705-13717.

77 Han J, Meng Q, Xi Q, Zhang Y, Zhuang Q, Han Y et al. Interleukin-6 stimulates aerobic glycolysis by regulating PFKFB3 at early stage of colorectal cancer. Int $\mathrm{J}$ Oncol 2016; 48: 215-224.

78 Bando H, Atsumi T, Nishio T, Niwa H, Mishima S, Shimizu C et al. Phosphorylation of the 6-phosphofructo-2-kinase/fructose 2,6-bisphosphatase/PFKFB3 family of glycolytic regulators in human cancer. Clin Cancer Res 2005; 11: 5784-5792.

79 Lu Q, Yan S, Sun H, Wang W, Li Y, Yang X et al. Akt inhibition attenuates rasfonininduced autophagy and apoptosis through the glycolytic pathway in renal cancer cells. Cell Death Dis 2015; 6: e2005

80 Reddy MM, Fernandes MS, Deshpande A, Weisberg E, Inguilizian HV, AbdelWahab $O$ et al. The JAK2V617F oncogene requires expression of inducible phosphofructokinase/fructose-bisphosphatase 3 for cell growth and increased metabolic activity. Leukemia 2012; 26: 481-489.

81 Feng Y, Wu L. mTOR up-regulation of PFKFB3 is essential for acute myeloid leukemia cell survival. Biochem Biophys Res Commun 2017; 483: 897-903.

82 Mendoza EE, Pocceschi MG, Kong X, Leeper DB, Caro J, Limesand KH et al. Control of glycolytic flux by AMP-activated protein kinase in tumor cells adapted to low pH. Transl Oncol 2012; 5: 208-216.

83 Lea MA, Altayyar M, desBordes $C$. Inhibition of growth of bladder cancer cells by 3-(3-pyridinyl)-1-(4-pyridinyl)-2-propen-1-one in combination with other compounds affecting glucose metabolism. Anticancer Res 2015; 35: 5889-5899.

84 Clem B, Telang S, Clem A, Yalcin A, Meier J, Simmons A et al. Small-molecule inhibition of 6-phosphofructo-2-kinase activity suppresses glycolytic flux and tumor growth. Mol Cancer Ther 2008; 7: 110-120.

85 Han J, Meng Q, Xi Q, Wang H, Wu G. PFKFB3 was overexpressed in gastric cancer patients and promoted the proliferation and migration of gastric cancer cells. Cancer Biomark 2016; 18: 249-256.

86 Marotta LL, Almendro V, Marusyk A, Shipitsin M, Schemme J, Walker SR, Bloushtain-Qimron $\mathrm{N}$ et al. The JAK2/STAT3 signaling pathway is required for growth of CD44(+)CD24(-) stem cell-like breast cancer cells in human tumors. J Clin Invest 2011; 121: 2723-2735.

87 Shipitsin M, Campbell LL, Argani P, Weremowicz S, Bloushtain-Qimron N, Yao J et al. Molecular definition of breast tumor heterogeneity. Cancer Cell 2007; 11: 259-273.

88 Cieslar-Pobuda A, Jain MV, Kratz G, Rzeszowska-Wolny J, Ghavami S, Wiechec E. The expression pattern of PFKFB3 enzyme distinguishes between inducedpluripotent stem cells and cancer stem cells. Oncotarget 2015; 6: 29753-29770.

89 Geudens I, Gerhardt H. Coordinating cell behaviour during blood vessel formation. Development 2011; 138: 4569-4583.

90 Potente M, Gerhardt H, Carmeliet P. Basic and therapeutic aspects of angiogenesis. Cell 2011; 146: 873-887.

91 De Bock K, Georgiadou M, Schoors S, Kuchnio A, Wong BW, Cantelmo AR et al. Role of PFKFB3-driven glycolysis in vessel sprouting. Cell 2013; 154: 651-663.

92 Dobrina A, Rossi F. Metabolic properties of freshly isolated bovine endothelial-cells. Biochim Biophys Acta 1983; 762: 295-301.

93 Secomb TW, Hsu R, Braun RD, Ross JR, Gross JF, Dewhirst MW. Theoretical simulation of oxygen transport to tumors by three-dimensional networks of microvessels. Adv Exp Med Biol 1998; 454: 629-634.

94 Gatenby RA, Gillies RJ. Why do cancers have high aerobic glycolysis? Nat Rev Cancer 2004; 4: 891-899.

95 Helmlinger G, Yuan F, Dellian M, Jain RK. Interstitial pH and pO2 gradients in solid tumors in vivo: high-resolution measurements reveal a lack of correlation. Nat Med 1997; 3: 177-182.

96 Folkman J. Tumor angiogenesis: therapeutic implications. N Engl J Med 1971; 285: 1182.

97 Tsutsui S, Kume M, Era S. Prognostic value of microvessel density in invasive ductal carcinoma of the breast. Breast Cancer 2003; 10: 312-319.

98 Offersen BV, Borre M, Overgaard J. Quantification of angiogenesis as a prognostic marker in human carcinomas: a critical evaluation of histopathological methods for estimation of vascular density. Eur J Cancer 2003; 39: 881-890.

99 Liu Z, Fan F, Wang A, Zheng S, Lu Y. Dll4-Notch signaling in regulation of tumor angiogenesis. J Cancer Res Clin Oncol 2014; 140: 525-536.

100 Vandekeere S, Dewerchin M, Carmeliet P. Angiogenesis revisited: an overlooked role of endothelial cell metabolism in vessel sprouting. Microcirculation 2015; 22: 509-517.
101 Hunt TK, Aslam RS, Beckert S, Wagner S, Ghani QP, Hussain MZ et al. Aerobically derived lactate stimulates revascularization and tissue repair via redox mechanisms. Antioxid Redox Signal 2007; 9: 1115-1124.

102 Jain Rakesh K. Antiangiogenesis strategies revisited: from starving tumors to alleviating hypoxia. Cancer Cell 2014; 26: 605-622.

103 Murata R, Nishimura Y, Hiraoka M. An antiangiogenic agent (TNP-470) inhibited reoxygenation during fractionated radiotherapy of murine mammary carcinoma. Int J Radiat Oncol Biol Phys 1997; 37: 1107-1113.

104 Cantelmo AR, Conradi LC, Brajic A, Goveia J, Kalucka J, Pircher A et al. Inhibition of the glycolytic activator PFKFB3 in endothelium induces tumor vessel normalization, impairs metastasis, and improves chemotherapy. Cancer Cell 2016; 30: $968-985$.

105 Roos D, Loos JA. Changes in the carbohydrate metabolism of mitogenically stimulated human peripheral lymphocytes. II. Relative importance of glycolysis and oxidative phosphorylation on phytohaemagglutinin stimulation. Exp Cell Res 1973; 77: 127-135.

106 Krauss S, Brand MD, Buttgereit F. Signaling takes a breath-new quantitative perspectives on bioenergetics and signal transduction. Immunity 2001; 15: 497-502.

107 Jones RG, Thompson CB. Revving the engine: signal transduction fuels $\mathrm{T}$ cell activation. Immunity 2007; 27: 173-178.

108 Chang CH, Curtis JD, Maggi LB, Faubert B, Villarino AV, O'Sullivan D et al. Posttranscriptional control of T cell effector function by aerobic glycolysis. Cell 2013; 153: $1239-1251$.

109 Dunn GP, Koebel CM, Schreiber RD. Interferons, immunity and cancer immunoediting. Nat Rev Immunol 2006; 6: 836-848

110 Telang S, Clem BF, Klarer AC, Clem AL, Trent JO, Bucala R et al. Small molecule inhibition of 6-phosphofructo-2-kinase suppresses t cell activation. J Transl Med 2012; 10: 95.

111 Grewal J, Ricthie J, Al Rayyan N, Telang S, Yaddanapudi K, Chesney J. 6-phosphofructo-2-kinase/fructose-2,6-biphosphatase 3 (PFKFB3) is necessary for human melanoma MDSC differentiation and function. J Immunol 2016; 196: 74.8.

112 Chesney JA, Telang S, Yaddanapudi K, Grewal JS. Targeting 6-phosphofructo-2kinase (PFKFB3) as an immunotherapeutic strategy. J Clin Oncol 2016; 34: e14548.

113 Telang S, Yaddanapudi K, Grewal J, Redman R, Fu S, Pohlmann P et al. Abstract B90: PFK-158 is a first-in-human inhibitor of PFKFB3 that selectively suppresses glucose metabolism of cancer cells and inhibits the immunosuppressive Th17 cells and MDSCs in advanced cancer patients. Cancer Res 2016; 76: B90.

114 Pearce EL, Poffenberger MC, Chang CH, Jones RG. Fueling immunity: insights into metabolism and lymphocyte function. Science 2013; 342: 1242454.

115 Everts B, Amiel E, Huang SC, Smith AM, Chang CH, Lam WY et al. TLR-driven early glycolytic reprogramming via the kinases TBK1-IKKvarepsilon supports the anabolic demands of dendritic cell activation. Nat Immunol 2014; 15: 323-332.

116 Krawczyk CM, Holowka T, Sun J, Blagih J, Amiel E, DeBerardinis RJ et al. Toll-like receptor-induced changes in glycolytic metabolism regulate dendritic cell activation. Blood 2010; 115: 4742-4749.

117 Trinchieri G. Inflammation in cancer: a therapeutic target? Oncology 2011; 25: 418-420.

118 Coussens LM, Werb Z. Inflammation and cancer. Nature 2002; 420: 860-867.

119 Lukas M. Inflammatory bowel disease as a risk factor for colorectal cancer. Digest Dis 2010; 28: 619-624.

120 Askling J, Dickman PW, Karlen P, Brostrom O, Lapidus A, Lofberg R et al. Family history as a risk factor for colorectal cancer in inflammatory bowel disease. Gastroenterology 2001; 120: 1356-1362.

121 Shaw G, Kamen R. A conserved AU sequence from the 3' untranslated region of GM-CSF mRNA mediates selective mRNA degradation. J Immunol 2012; 189: 5-13.

122 Liu H, Hu Y, Savaraj N. Hypersensitization of tumor cells to glycolytic inhibitors. Biochemistry 2001; 40: 5542-5547.

123 Pisarsky L, Bill R, Fagiani E, Dimeloe S, Goosen Ryan W, Hagmann J et al. Targeting metabolic symbiosis to overcome resistance to anti-angiogenic therapy. Cell Reports 2016; 15: 1161-1174.

124 Clem BF, O'Neal J, Tapolsky G, Clem AL, Imbert-Fernandez Y, Kerr DA et al. Targeting 6-phosphofructo-2-kinase (PFKFB3) as a therapeutic strategy against cancer. Mol Cancer Ther 2013; 12: 1461-1470.

125 Brooke DG, van Dam EM, Watts CK, Khoury A, Dziadek MA, Brooks $\mathrm{H}$ et al. Targeting the Warburg effect in cancer; relationships for 2-arylpyridazinones as inhibitors of the key glycolytic enzyme 6-phosphofructo-2-kinase/2,6-bisphosphatase 3 (PFKFB3). Bioorg Med Chem 2014; 22: 1029-1039.

126 Lea MA, Guzman Y, Desbordes C. Inhibition of growth by combined treatment with inhibitors of lactate dehydrogenase and either phenformin or inhibitors of 6-phosphofructo-2-kinase/fructose-2,6-bisphosphatase 3. Anticancer Res 2016; 36: $1479-1488$. 
127 Seo M, Kim JD, Neau D, Sehgal I, Lee YH. Structure-based development of small molecule PFKFB3 inhibitors: a framework for potential cancer therapeutic agents targeting the Warburg effect. PLOS ONE 2011; 6: e24179.

128 Wang H, Xie H, Wu J, Wei X, Zhou L, Xu X et al. Structure-based rational design of prodrugs to enable their combination with polymeric nanoparticle delivery platforms for enhanced antitumor efficacy. Angew Chem 2014; 126: 11716-11721.

129 Wang H, Xie H, Wang J, Wu J, Ma X, Li L et al. Self-assembling prodrugs by precise programming of molecular structures that contribute distinct stability, pharmacokinetics, and antitumor efficacy. Adv Funct Mater 2015; 25: 4956-4965.

130 Wang H, Wu J, Xie K, Fang T, Chen C, Xie H et al. Precise engineering of prodrug cocktails into single polymeric nanoparticles for combination cancer therapy: extended and sequentially controllable drug release. ACS Appl Mater Interfaces 2017; 9: 10567-10576.

131 Akter S, Clem BF, Lee HJ, Chesney J, Bae Y. Block copolymer micelles for controlled delivery of glycolytic enzyme inhibitors. Pharm Res 2012; 29: 847-855.

132 Wu H, Ding Z, Hu D, Sun F, Dai C, Xie J et al. Central role of lactic acidosis in cancer cell resistance to glucose deprivation-induced cell death. J Pathol 2012; 227: 189-199.
133 Chao M, Wu H, Jin K, Li B, Wu J, Zhang G et al. A nonrandomized cohort and a randomized study of local control of large hepatocarcinoma by targeting intratumoral lactic acidosis. Elife 2016; 5: e15691.

134 Santos CR, Schulze A. Lipid metabolism in cancer. FEBS J 2012; 279: 2610-2623.

135 Zadra G, Photopoulos C, Loda M. The fat side of prostate cancer. Biochim Biophys Acta 2013; 1831: 1518-1532.

136 Buzzai M, Bauer DE, Jones RG, DeBerardinis RJ, Hatzivassiliou G, Elstrom RL et al. The glucose dependence of Akt-transformed cells can be reversed by pharmacologic activation of fatty acid beta-oxidation. Oncogene 2005; 24: 4165-4173.

(c) (i)

This work is licensed under a Creative Commons Attribution 4.0 International License. The images or other third party material in this article are included in the article's Creative Commons license, unless indicated otherwise in the credit line; if the material is not included under the Creative Commons license, users will need to obtain permission from the license holder to reproduce the material. To view a copy of this license, visit http://creativecommons.org/licenses/ by/4.0/

(c) The Author(s) 2017

Supplementary Information accompanies the paper on the Signal Transduction and Targeted Therapy website (http://www.nature.com/sigtrans) 